\section{Abscisic Acid Content in Chilled Tomato Fruit}

\author{
P.M. Ludford and L.L. Hillman \\ Department of Vegetable Crops, Cornell University, Plant Science \\ Building, Ithaca, NY 14853
}

Additional index words. Lycopersicon esculentum, chilling injury, ripening, ABA isolation

Abstract. Free abscisic acid (ABA) was determined in pericarp of mature-green to-
mato fruit before and after chilling at $2 \mathrm{C}$ for 12 days, in chilling-sensitive and chilling-
tolerant cultivars. After being ripened at $20 \mathrm{C}$, these fruit were compared with field-
ripened fruit. Chilled fruit contained 2 to 3 times the amount of free ABA as did
unchilled. The ABA isolation method described involves the use of preparative and
analytical high performance liquid chromatography followed by gas chromatography.

Tomato fruit are sensitive to chilling at the mature-green (MG) stage (Morris, 1982), but often show little visible damage until ripening, when there is uneven color development, pitting, and decay. Crooks (1985) examined various physiological characteristics to try to distinguish differences between chilling-sensitive and chilling-tolerant fruit at the chilled MG stage, before visible injury is evident. Chilling temperatures result in an ABA increase in plant tissues, e.g., tomato seedlings (Daie and Campbell, 1981). In this paper, we report on differences in free $A B A$ content between chilled and nonchilled tomato fruit of sensitive and tolerant lines and describe a reproducible method of ABA isolation using preparative and analytical high performance liquid chromatography (HPLC) for purification and separation.

Tomatoes were grown in 1984 and 1986 with three replications in a randomized complete-block design at the Homer C. Thompson Vegetable Research Farm, Freeville, N.Y. All were Lycopersicon esculentum Mill., except one cross with $L$. pimpinellifolium (line 281). Of the four lines grown, two were normal large-fruiited types and two were cherry types. One of each was chilling-sensitive, 'New Yorker' (NY, large-fruited) and 'Early Cherry' (EC, small-fruited). The others were chilling-tolerant lines, 79-546 (79, largefruited) and 281 (cherry).

Fruit were harvested at the MG stage, calyces and pedicels removed. washed in tepid water, dipped in a 300-ppm chlorine solution for 3 rein, and air-dried. The three replications, maintained throughout the treatments, were divided at random on trays for chilling and nonchilling treatments. Nonchilled fruit were ripened at 20C. Chilling treatment was

Received for publication 16 June 1989. We thank R.W. Robinson (New York State Experimental Station, Geneva) for the chilling-tolerant lines. Use of trade names does not imply endorsement of the products named nor criticism of similar products not mentioned. Vegetable Crops Dept. paper no. 887. The cost of publishing this paper "was defrayed in part by the payment of page charges. Under postal regulations, this paper therefore must be hereby marked advertisement solely to indicate this fact.
2C for 12 days followed by ripening at $20 \mathrm{C}$ ( $\approx 14$ days). Fruit were also picked ripe from the field and sampled immediately, coincident with those held a total of $\approx 26$ days.

In 1986, only NY and 79 (large-fruited) fruit were harvested MG and subjected to chilling, but sampling was at the MG, turning, pink- and red-ripe stages. These stages three replications). $281=$ line 281 , cherry, chilling-tolerant. were also sampled directly from the field. In 1984, containers of water were placed in front of the fan in the storage rooms (average $90 \%$ $\mathrm{RH}$ at $2 \mathrm{C}$ and $68 \% \mathrm{RH}$ at $20 \mathrm{C}$ ). In 1986, tomatoes were placed in buckets laid sideways on shelves, with the open bucket draped by wet cheesecloth with a continuous drip, with an average $95 \% \mathrm{RH}$ at $2 \mathrm{C}$ and $91 \% \mathrm{RH}$ at $20 \mathrm{C}$.

At the time of sampling (three single fruit per replication), the fruit were separated into pericarp and seeds, immediately frozen in liquid $\mathrm{N}_{2}$, and held at $-20 \mathrm{C}$ for up to 3 days until lyophilization. The freeze-dried pericarp of each single-fruit sample was ground in a Wiley mill with a 40-mesh grid.

All distilled water used in ABA extraction and isolation was millipore-filtered, and all organic solvents used were HPLC grade (Burdick and Jackson, Muskegon, Mich.). Samples of $40 \mathrm{mg}$ dry weight (DW) were extracted with $4 \mathrm{ml} 80 \%$ cold methanol, with stirring, for $1 \mathrm{hr}$ in darkness at $0 \mathrm{C}$ (we determined this interval during preliminary tests). Sample size was determined by running a DW curve (1 to $100 \mathrm{mg}$; $100 \mathrm{ml}$ methanol/DW) to optimize the level of ABA without overloading the columns (Fig. 1).

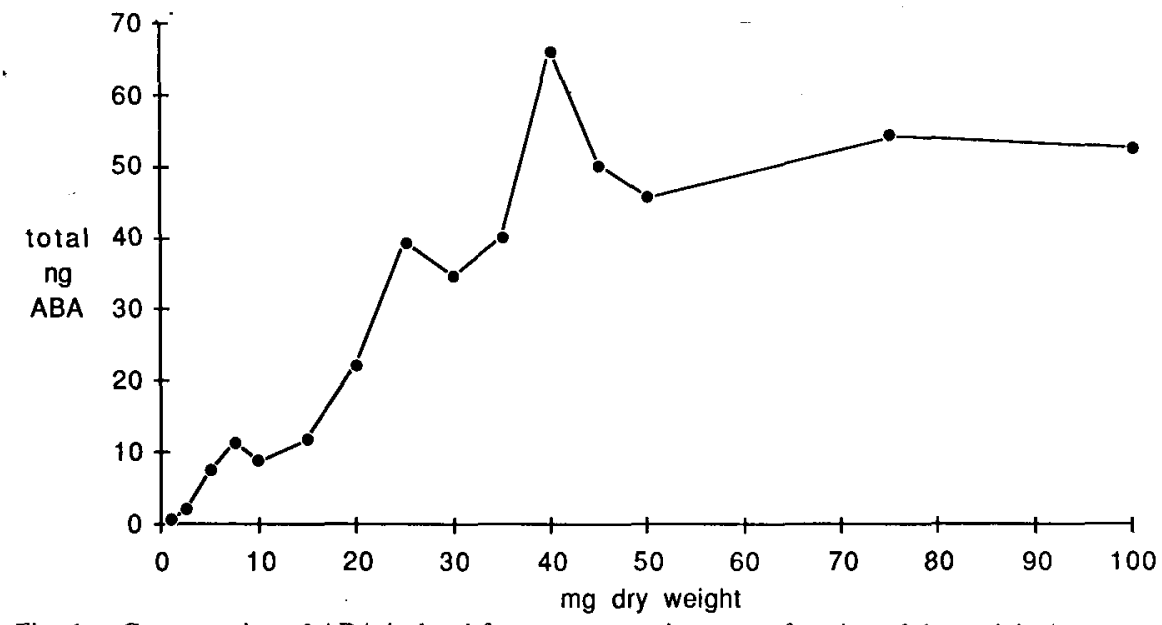

Fig. 1. Concentration of $A B A$ isolated from tomato pericarp as a function of dry weight (average of

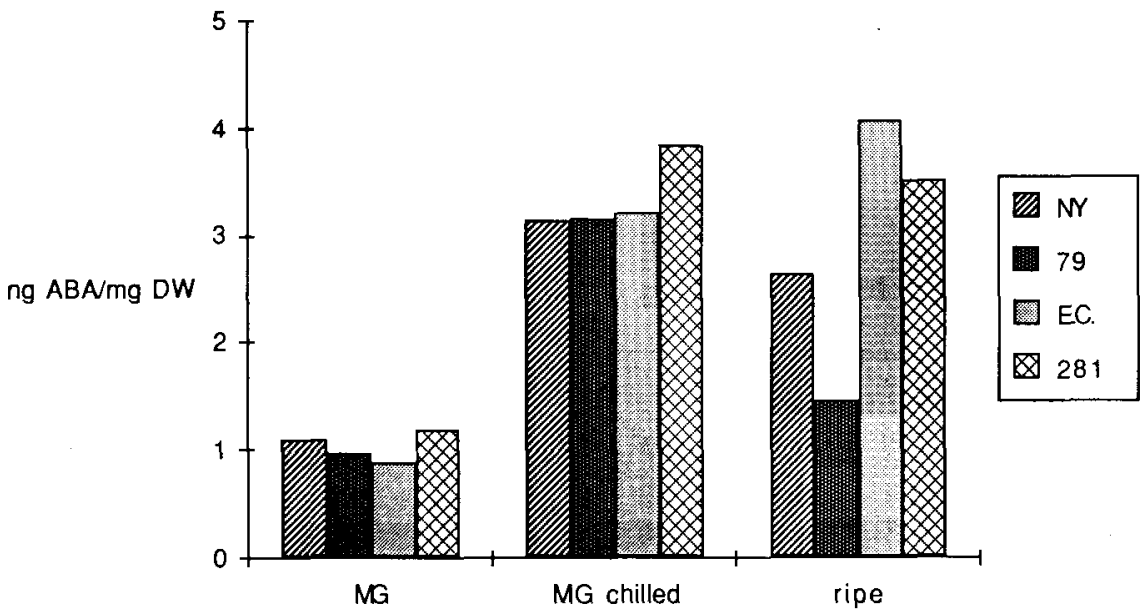

Fig. 2. Free ABA content in chilled and nonchilled MG tomato fruit: chilled fruit subsequently were ripened in a 20C chamber (1984). NY = 'New Yorker', large-fruited, chilling-sensitive; EC = 'Early Cherry', small-fruited, chilling-sensitive; $79=$ line 79-546, large-fruited, chilling-tolerant; 


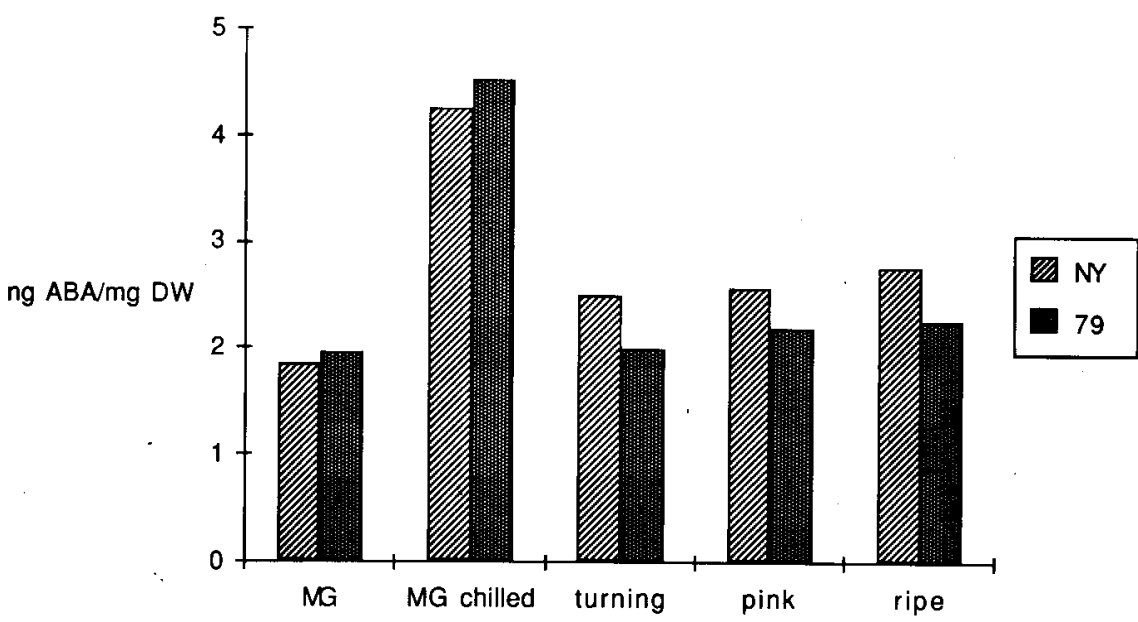

Fig. 3. Free ABA content in chilled and nonchilled MG tomato fruit, the chilled fruit subsequently were ripened in a $20 \mathrm{C}$ chamber (1986). NY = 'New Yorker', large-fruited, chilling-sensitive; 79 $=$ line 79-546, large-fruited, chilling-tolerant.

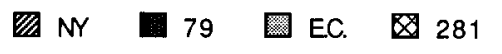

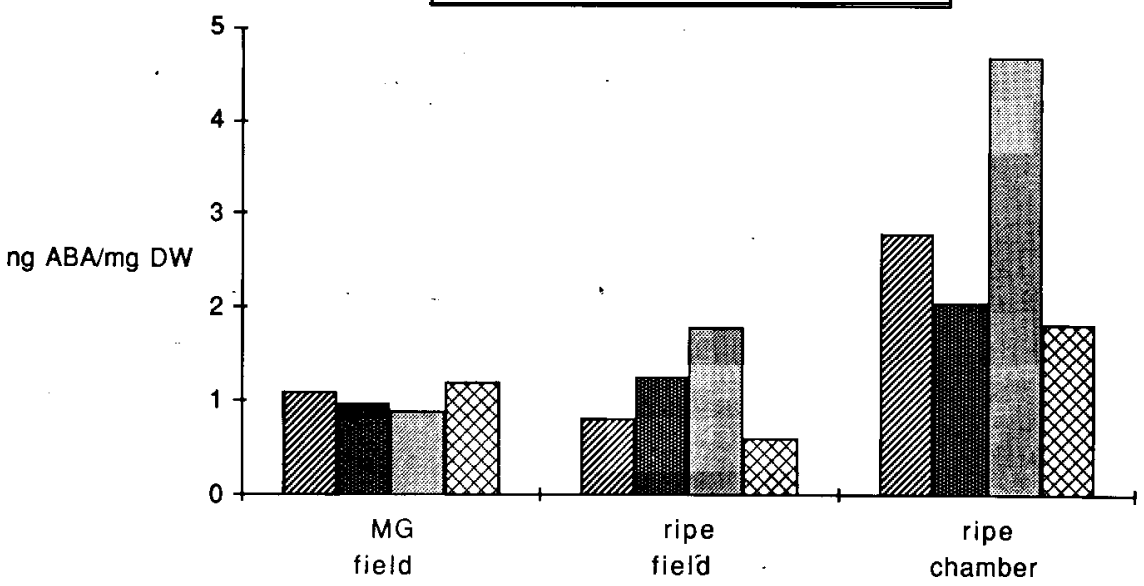

Fig. 4. Free $A B A$ content in field-picked $M G$ and ripe tomato fruit, and in nonchilled $M G$ fruit ripened in a $20 \mathrm{C}$ chamber (1984). NY = 'New Yorker', large-fruited, chilling-sensitive; EC = 'Early Cherry', small-fruited, chilling-sensitive; $79=$ line 79-546, large-fruited, chilling-tolerant; $281=$ line 281 , cherry, chilling -tolerant.

Table 1. Differences in ABA content and their significance between control and chilled tomato fruit, both chilling-sensitive and tolerant.

\begin{tabular}{lcccc}
\hline \hline Year & Lines $^{2}$ & $\begin{array}{c}\text { Difference } \\
\text { (ng ABA/mg DW) }\end{array}$ & $t$ value & $\operatorname{Pr}>t$ \\
\hline 1984 & NY & $2.04 \pm 0.62$ & 3.29 & 0.0110 \\
1984 & 79 & $2.18 \pm 0.62$ & 3.51 & 0.0080 \\
1984 & EC & $2.33 \pm 0.62$ & 3.76 & 0.0056 \\
1984 & 281 & $2.66 \pm 0.62$ & 4.28 & 0.0027 \\
1986 & NY & $2.33 \pm 0.46$ & 5.05 & 0.0010 \\
1986 & 79 & $2.56 \pm 0.46$ & 5.57 & 0.0005 \\
\hline
\end{tabular}

${ }^{2} \mathrm{NY}=$ 'New Yorker', large-fruited, chilling-sensitive; EC $=$ 'Early Cherry', small-fruited, chillingsensitive; $79=$ line $79-546$, large-fruited, chilling-tolerant; $281=$ line 281 , cherry, chilling-tolerant.

The extracts were millipore-filtered $(1.2 \mu \mathrm{m}$ pore size), rinsed, and vacuum-evaporated at $28 \mathrm{C}$ to the aqueous phase. The $\mathrm{pH}$ was adjusted to 3.5 , and the sample was partitioned three times against an equal volume of chloroform that was then evaporated.

The HPLC method for ABA isolation (Horgan, 1981) was based on that of Ciha et al. (1977). An Altex 110A HPLC system (Altex, Fullerton, Calif.) had a preparative column $(250 \times 10 \mathrm{~mm}$, Altex Ultrasil-ODS, particle size $10 \mu \mathrm{m})$ and an analytical col- bance at $254 \mathrm{~nm}$ and recorded by integrator. The ABA peak (predetermined by standards, Sigma, St. Louis) was collected, partitioned at $\mathrm{pH} 3.5$, and dried as described above. A sample of $40 \mu$ ll (25\% methanol) was injected into a $20-\mu 1$ injector loop of the analytical column, the mobile phase being $30 \%$ methanol for $5 \mathrm{~min}$, followed by a gradient to $60 \%$ for $20 \mathrm{~min}$ with a flow rate of 0.7 $\mathrm{ml} \cdot \mathrm{min}^{-1}$. The ABA peak was collected, partitioned, and dried as with the preparative column.

To the sample in $25 \mu 1100 \%$ methanol was added an internal standard of 2(2-chlorophenyl)-2(4-chloro-phenyl)-1, 1, 1-trichloro-ethane $\left(\mathrm{O}, \mathrm{P}^{\prime}-\mathrm{DDT}\right)$ as $0.5 \mathrm{ng} / \mu / 1$, along with $0.1 \mathrm{ml}$ of methylated ether. Methylation involved diazomethane by the use of $N$ methyl-N-nitroso-p-toluenesulfonamide (Diazald), as described by Schlenk and Gellerman (1960). After vortexing and a wait of 10 rein, the samples were dried under $\mathrm{N}_{2}$ and dissolved in $25 \mu$ ll ethyl acetate. Injections of $2 \mu$.1 were made onto a 3 -m glass column (6 $\mathrm{mm}$ o.d., $2 \mathrm{~mm}$ id., packed with OV17; Supelco, Bellefonte, Pa.) of the gas chromatography (Hewlett-Packard 5730A). The injector was at $300 \mathrm{C}$, the oven had a gradient from 220 to $280 \mathrm{C}$ at $2 \mathrm{C} / \mathrm{min}$, and the carrier gas was $5 \%$ methane and $95 \%$ argon. Detection was by electron capture at $300 \mathrm{C}$ and recording was by an integrator.

Recovery of ABA was $72 \%$ (a range of $68 \%$ to $78 \%$ ), estimated by running $40-\mathrm{mg}$ samples through the procedure with and without the addition of $200 \mathrm{ng}$ of ABA. The difference between regular and spiked samples was calculated as percentage recovery. Verification of ABA was made using mass spectrometry (GC-MS) in representative samples [Finnigan (San Jose, Calif.) model 1015 GC-MS and System Industries Data System, operated by the Dept. of Chemistry, Cornell Univ.].

The method used here for ABA isolation has proved to be reproducible, using the same weight of tissue for extraction. Comparative extraction times demonstrated that $1 \mathrm{hr}$ was sufficient $(0.79 \pm 0.03$ and $0.73 \pm 0.03 \mathrm{ng}$ $\mathrm{ABA} / \mathrm{mg}$ DW after 1 and $24 \mathrm{hr}$ duration with stirring, respectively). Details of the method and the DW of lyophilized tissue extracted vary among kinds of plant, so that slight modifications are needed. For potato tubers, squash fruit, and cabbage heads, a polyvinylpolypyrrolidone (PVPP) treatment is necessary to remove phenols and clean the extract before injecting onto HPLC columns.

In both years, the effect of 12 days chilling at $2 \mathrm{C}$ was a 2- to 3-fold increase in free ABA $(\mathrm{P}=0.0001)$. This was the case in both 1984 (Fig. 2) and 1986 (Fig. 3), whether the line was sensitive or tolerant (Table 1). The results of the 1984 experiment could have been influenced by water loss. However, similar results from the more controlled humidity conditions of the 1986 experiment suggest that chilling was primarily responsible. Thus, chilling of MG tomato fruit resulted in an increase in free ABA content in tomato fruit pericarp, regardless of cultivar, chilling-sensitivity, or fruit type (large vs. 


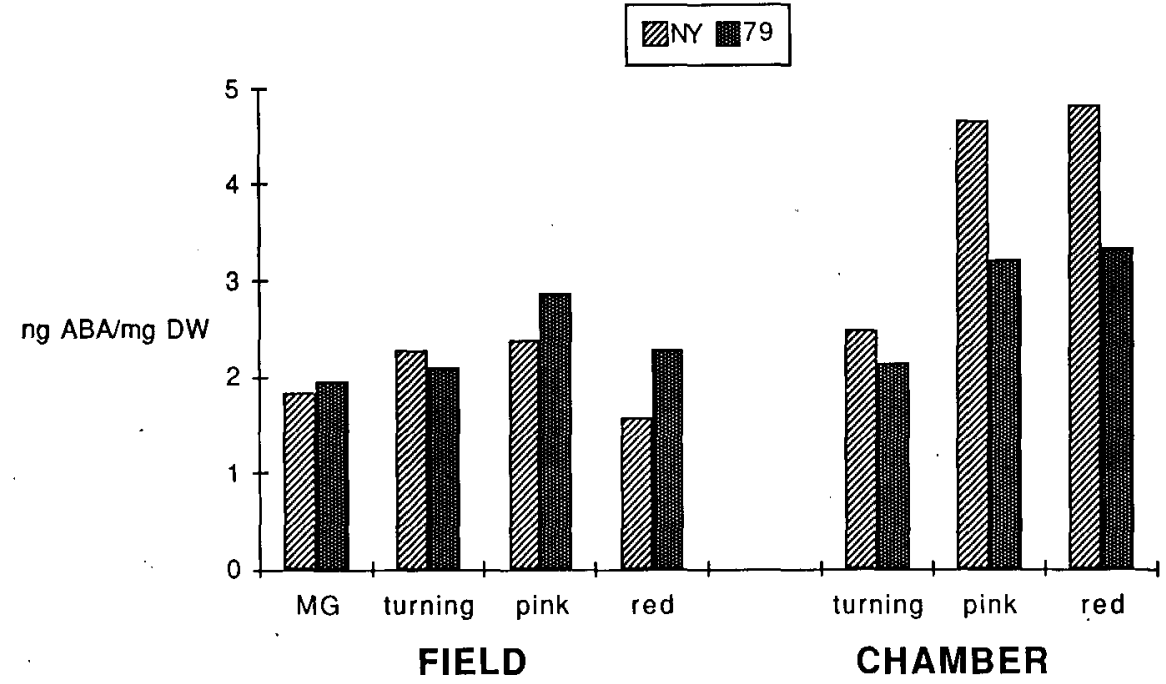

Fig. 5. Free ABA content in field-harvested MG, turning, pink, and ripe tomato fruit, and in nonchilled MG fruit ripened in a 20C chamber (1986). NY = 'New Yorker', large-fruited, chilling-sensitive; $79=79-546$, large-fruited, chilling-tolerant.

cherry). Exogenous ABA pretreatment gave some protection against chilling injury in cotton (Rikin et al., 1979) and reduced symptoms of damage in cucumber seedlings (Sasson and Bramlage, 1981).

When chilled tomatoes were ripened at 20C, there was a significant decrease in ABA content of the large-fruited NY and 79 (Figs. 2 and 3$)$ in $1984(\mathrm{P}=0.0019)$ and $1986(\mathrm{P}$ $=0.0001)$, in contrast to cherry fruit (EC and 281), where ABA remained near the high value for chilled fruit (Fig. 2). The drop in ABA content from the high value in the chilled MG fruit to that in the ripened large fruit was noticeable even at the turning stage (Fig. 3; $P=0.0001)$. There were nonsignificant differences between chilling-sensitive and tolerant lines. The chilled and ripened chilling-sensitive NY had a tendency for higher ABA content than the similarly treated tolerant line 79 in 1984 and 1986 (Figs. 2 and 3 ), and a chilled and ripened chilling-sensitive EC tended to have a higher ABA content than tolerant 281 (Fig. 2), suggesting that the tolerant lines can ripen after chilling off, as with field-ripened fruit (Fig. 5), possibly due to the time involved after harvest $(\approx 12$ to 14 days in the ripening room). This was the case in 1984 and 1986 at both humidities.

\section{Literature Cited}

Ciha, A. J., M.L. Brenner, and W.A. Brun. 1977. Rapid separation and quantification of abscisic acid from plant tissues using high performance liquid chromatography. Plant Physiol. 59:821826.

Crooks, J.R. 1985. Chilling injury in tomato fruit cultivars with different sensitivities to low temperature. PhD Diss., Cornell Univ., Ithaca, N.Y.

Daie, J. and W.F. Campbell. 1981. Response of tomato plants to stressful temperatures: Increase in abscisic acid concentrations. Plant Physiol. 67:26-29.

Horgan, R. 1981. Modern methods for plant hormone analysis, p. 137-170. In: L. Reinhold, J.B. Harborne, and T. Swain (eds.). Progress in photochemistry. Pergamon Press, New York.

King, M.M. and P.M. Ludford. 1983. Chilling injury and electrolyte leakage in fruit of different tomato cultivars. J. Amer. Soc. Hort. Sci. 108:74-77.

Lyons, J. M., J.K. Raison, and P.L. Steponkus. 1979. The plant membrane in response to low temperature: An overview, p. 1-24. In: J.M. Lyons, D. Graham, and J.K. Raison (eds.). Low temperature stress in crop plants: The role of the membrane. Academic, New York.

McGlasson, W.B. 1978. Role of hormones in ripening and senescence, p. 77-96. In: H.O. Hultin and M. Milner (eds.). Postharvest biology and biotechnology. Food and Nutrition Press, Westport, Conn.

Morris, L.L. 1982. Chilling injury of horticultural crops: An overview. HortScience 17:161-162.

Rikin, A., D. Atsmon, and C. Gitler. 1979. Chilling injury in cotton (Gossypium hirsutum L.): Prevention by abscisic acid. Plant Cell Physiol. 20:1537-1546.

Sasson, N. and W.J. Bramlage. 1981. Effects of chemical protestants against chilling injury of young cucumber seedlings. J. Amer. Hort. Sci. 106:282-284.

Schlenk, H. and J.L. Gellerman. 1960. Esterification of fatty acids with diazomethane on small scale. Anal. Chem. 32:1412-1414. 